\title{
Examining Rental Housing Affordability Among Eastern Ethiopian Cities
}

\author{
Abaynew Wudu Belete \\ FDRE Policy Studies Institute, Addis Ababa, Ethiopia
}

\begin{abstract}
The rental sector had been neglected in government housing policy and in the local government's resource allocation, though it apprehended a large number of urban dwellers and which will undoubtedly continue in the future. The study aimed to examine the rental housing affordability, assess rental housing characteristics, identify factors which determined rental affordability and devised alternatives to promote rental housing affordability. In examining rental affordability about 651 questionnaires were distributed to rental households and government officials were interviewed to capture experience on rental regulatory and administrative issues. Global and local experiences on government housing policy and strategies revealed that the rental housing was less emphasized or sometimes, it was totally ignored. However, results from inter-census survey report revealed that the rental sectors had contributed much in addressing the residential needs of the urban poor and the contribution of the sector in addressing the housing needs were raised from 45 percent to 54 percent. Results from the logistic regression analysis indicated us the rental levels in the sample cities were in the threshold at least for 60 percent of the households. However, this event does not mean that rent is affordable; rather the lessee had a compromised adequacy of housing with monthly rental price to be in acceptable range. Therefore, the government should devise alternatives to promote rental sectors through regulation and policy interventions. Among the possible measures, getting rental housing on the larger urban policy is the first and central intervention. The government should regulate the rental market through regulatory and policy measures by making balance the interests of both landlords and renters.
\end{abstract}

Keywords: need for rental housing, rent affordability, housing condition, measures of affordability

DOI: $10.7176 / \mathrm{DCS} / 9-6-05$

Publication date:June $30^{\text {th }} 2019$

\section{Introduction}

1.1 Background of the study

Housing is one of the necessities for humans, and it accounts for the largest share of household consumption expenditure. Though their motives vary, the private sector, the public sector, and civil societies are already producing housing. However, production falls far short of providing a decent and affordable shelter for all urban households. Thus, many those who cannot have enough money to live in the formal market are pressured to share housing with family or friends or to lease (UN-HABITAT, 2008).

While the prevalence of renting varies considerably across the world, rental housing accommodates much urban residents. Figures from the United Nations Population Center indicated that an estimated 1.2 billion world wide's population is accommodated in rental housing. In Seoul, the number of renters rose from 883,000 in 1960 to 5.7 million in 1985. The proportions of rentals are higher than that of owners in the developed countries than the developing countries, though the size is significant even for the less developed countries. About 66 percent of housing tenure in Berlin, 55 percent in New York, 41 percent in London, 54 percent in Montreal and 74 percent in Amsterdam were accommodated in the rental arrangements. In developing countries, for example, from 19942001, 63 percent of housing tenure in Cairo, 82 percent in Kisumu, 63 percent in Addis Ababa, 49 percent in Lagos, 42 percent in Johannesburg and 41 percent in Bangkok were rentals (UN-HABITAT, 2003).

The need for renting depends on socioeconomic and demographic dynamics. Migrants from the countryside to urban areas, new job seekers who recently joined the labor market, divorced or separated families, may all rely at least temporarily on rental housing. For others, renting is a permanent or semi-permanent state because ownership, whether in the formal or the informal sector, is unavoidable. Whatever the cause, a common feature of housing in most developing countries is that the number of urban families living in rented or shared housing has usually increased. Rapid urbanization and the resulting population growth, both through migration and natural increase have stimulated most migrants and new urban households initially to rent or share accommodation (UN-HABITAT, 2011).

In Ethiopia, though, the numbers of renters are significant in numbers, the rental sectors had been neglected in government housing policy and in the local government's resource allocation. Urban housing policy is biased to ownership. Thus, the lessees are vulnerable to social, economic and environmental crises. Rented households are forced to pay for an extra amount beyond the market value and owners have the privilege to collect a rental value whatever they considered reasonable and can expel renters' if they wish to raise the lease sum. Arbitrary increases in rent levels often force rented households to make frequent changes in their accommodation 
invariably affecting their access to transport and social services such as education and health services. Families who have school-age children are highly indebted to high rent values as they are not ready to change to convenience sites effectively. When, the household size increases, it is not always easy to find an affordable rental house. Though plenty of works were made to address housing challenges from the perspectives of ownership, the rental sector was uncovered adequately. Therefore, the study was aimed to evaluate and identifies determinant factors that affect rent affordability.

\subsection{Problem statement}

Housing is the prime problems existed in the Ethiopian urban situation. Government reports and study results confirmed that Ethiopia is experiencing a dire shortage of housing. The two census results conducted in 1994 and 2007 revealed that there was a shortage of 92 and 128.3 thousand of housing shortages. The results of both censuses confirmed that the shortage of housing unit is a persistent problem. The government estimates that the current housing deficit is between 900,000 and 1,000,000 units in urban areas and that only 30 percent of the current housing stock is in fair condition, with the remaining 70 percent needs improvements or in some cases total replacement. During the Growth and Transformation Period (2004-2015), some were projected Ethiopia needs an additional units of 250000 housing units per year in addition to the current backlogs (Ministry of Urban Development, Housing and Construction (MUDHCo), 2015)

In recognizing that problem, the government has put in place various strategies and programs and government of Ethiopia was targeted to build an addition 2250831 housing unit/225000 housing unit per year/ to reply for the current needs in addition to filling the existing backlogs (The World Bank, 2015). Nonetheless, the strategies designed to address such a problem were focused on the ownership aspects and ignored one side of the solution for housing i.e., the rental market as one can be observed from housing policy and program documents. In the last decade, governments have spent much of resources for government-sponsored housing programs and projects. Funds were often made available for the construction of low-cost housing, and a self-help housing program intended to alleviate shelter problems.

Despite the government has made efforts to achieve housing ownership, especially on governmentsupported housing programs (integrated housing program/condominium/low-cost housing program, cooperatives/self-help housing program and real estate developments, studies on housing affordability indicated that only 35.9 percent of households in urban Ethiopia is able to afford or have the capacity to buy a low-cost housing supplied at a construction cost of US\$ 7397 (Center for Affordable Housing Finance in Africa, 2017). It implied many urban residents are likely to be sheltered in a less prioritized housing policy option or they are burdened with the cost of living. Housing affordability has a many effect housing access, health, labor market performance, finance, community sustainability, economic development, and urban and regional integration. Therefore, it is imperative to have a thorough understanding of the situation of the rental sector and come out with a possible alternative to address the problems. The main purpose of this study is to evaluate how rental housing is affordable from the perspectives of rental households and identified alternative affordability. In particular, the study was aimed at evaluating rental housing affordability and explored variables that affect rental affordability within the study areas.

\subsection{The objective of the study}

The objective of this study is to examine the rental housing affordability and its implication for low-income households. Specifically, assess the characteristics of rental housing, examined rent affordability, identify factors that determined rental affordability significantly and devised a possible alternative that can enhance rental housing affordability.

\subsection{Methodology}

1.4.1 Sampling technique and sample size

Spatially, the study focused on the eastern Ethiopian cities, Dire Dawa, Harar and Jigjiga. The cities found along the Ethiopian-Djibouti rail route and are the trade service centers of eastern Ethiopia. The cities share common values and are centers of commerce, though the population of Dire Dawa is doubled Jijiga and Harar. Contentwise, the study focused on the current rental housing conditions, affordability and regulatory environments governing the sector.

The sampling frame for the collection of data is rental units in the east Ethiopian cities. Disaggregated data on the number of rental households revealed that 8045 households in Jigjiga, 16691 households in Dire Dawa and 9249 households were lived in a privately rented house (CSA, 2007). Based on the research advisor 2006 required sample size determination table, the recommended sample size for a population size of 34,907 with a 99 percent level of confidence and a 5 percent margin of error is about 651 .

Both quantitative and qualitative data had collected both from primary and secondary sources. Primary data had been collected from 651 households living in a rental house using structured and semi-structured 
questionnaires. The secondary data were collected from different sources including books, journals, official documents (government housing policies, strategies, and reports), aimed at comprehending local and international experiences. Furthermore, officials were interviewed and focused group discussions were conducted to capture their experience on regulatory and administrative issues.

1.4.2 Logistic Model Specification

Logistic regression sometimes called the logistic model or logit model used to analyze the relationship between independent variables and a categorical dependent variable and estimates the probability of an occurrence of an event by fitting data to a logistic curve. Binary logistic regression is used when the dependent variable is dichotomous and the independent variables are either continuous or categorical (Park, 2013).

A household spends less than or equals to 30 percent of their income is categorized as affordable and households that spend more than $30 \%$ of household monthly income were categorized as not affordable. A binary logistic regression analysis helps us to estimate whether a rental unit was within a threshold level of a household income or not. It enabled us to estimate the probability that an event occurs or not by predicting a binary dependent outcome from a set of observable independent variables.

$\mathrm{Yi}=\beta 0+\beta 1 \times 1 \mathrm{i}+\beta 2 \times 2 \mathrm{i}+\ldots+\beta \mathrm{nxni}+\varepsilon \mathrm{i}$

Let's take into consideration the indicator variable;

$\mathrm{Yi}=$ the outcome variable predicted from the equation

$\mathrm{Xi}=$ the explanatory variables explaining affordability

$\beta$ `s $=$ a vector of regression coefficient to be estimated and

$\varepsilon i=$ the error terms

Table 1: Description of Explanatory Variables in the Logistic Model

\begin{tabular}{|c|c|c|c|}
\hline Variable & Types & Description & Expected sign \\
\hline \multicolumn{4}{|c|}{ Dependent variables } \\
\hline Rent affordability & Binary & $0=$ Not affordable, $1=$ Affordable & \\
\hline \multicolumn{4}{|c|}{ Explanatory variables } \\
\hline Marital status of the household head & Categorical & $\begin{array}{c}1=\text { single } \\
0=\text { married } \text {, divorced and widowed }\end{array}$ & $-/+$ \\
\hline \multirow[t]{6}{*}{ Household income range } & \multirow[t]{6}{*}{ Categorical } & $<1600$ & \multirow[t]{6}{*}{+} \\
\hline & & $1600-3600$ & \\
\hline & & $3601-5600$ & \\
\hline & & $5601-7600$ & \\
\hline & & $7601-9600$ & \\
\hline & & $>9600$ & \\
\hline \multirow[t]{4}{*}{ Room size } & \multirow[t]{4}{*}{ Categorical } & Single Room & \multirow[t]{4}{*}{-} \\
\hline & & Two Room & \\
\hline & & Three Room & \\
\hline & & Four \& Above Room & \\
\hline \multirow[t]{4}{*}{ Household size } & \multirow[t]{4}{*}{ Categorical } & $1-2$ & \multirow[t]{4}{*}{$+/-$} \\
\hline & & $3-5$ & \\
\hline & & $5-7$ & \\
\hline & & 8 And Above & \\
\hline Availability of metered electricity & Binary & $0=N o, 1=Y e s$ & - \\
\hline Availability of private tape water & Binary & $0=N o, 1=Y e s$ & - \\
\hline Availability of kitchen/dining room & Binary & $0=N o, 1=Y e s$ & - \\
\hline \multirow[t]{3}{*}{ City/Town rank } & \multirow[t]{3}{*}{ Categorical } & Large City & \multirow[t]{3}{*}{$+/-$} \\
\hline & & Small Town & \\
\hline & & Medium City & \\
\hline
\end{tabular}

\subsubsection{Threshold affordability line}

Threshold line for rent affordability is calculated by dividing the per capital rent by household's income and multiplying by 100. A rental unit which incurred 30 percent or less of households' income is categorized as affordable and housing units which incurred more than 30 percent of household income to rent payment is categorized as unaffordable. Accordingly, the rental housing unit that was within the affordable range is coded as affordable (1) and housing units which labeled as not affordable are coded as affordable (0).

\section{Review literature}

\subsection{The need for a rental housing}

The ownership of one's home is a widespread ambition and is the focus of most national housing policies. Worldwide, governments have sought to encourage owner-occupation of fully-serviced single-household 
dwellings. But in Asia, Africa, and Latin America, this event has often only been feasible for middle and highincome groups. Today, a consensus is reached among different policymakers and urban development experts on the problems of the ownership approach in addressing the housing challenges. UN-Habitat recommended proownership housing policies must be changed and try to do something practical to help those members of society who live in rental housing, and those who can provide rental housing. However, empirical evidence on rental housing indicated that too few governments had recognized renting as the best alternative to too many people at particular points in their lives, especially during the early age of the housing career and towards the end.

Despite the effort and financial expenditure so many governments have spent to expand homeownership, rental housing still constitutes a large component of the housing stock in many countries. In Delhi, for example, the number of tenant households rose from 324,000 in 1961 to 545,000 twenty years later. In Seoul, there was an incredible rise in the number of renters, from 883,000 in 1960 to 5.7 million in 1985.

For individuals the reason to choose rental housing over ownership vested on different factors such as the flexibility to move to more attractive units as income rises, households may lack the income to down payment to buy for housing or build their house or be unable to access credit facilities. Furthermore, individuals might get direct rental subsidies from governments. For instance, in the Netherlands, qualified renters can get direct financial assistance and there has been a voucher system in the United States.

\subsection{Definition and measures of affordability}

A survey of literature on housing affordability revealed that there is no consensus among academics and housing development experts on the definition and measures of affordability. The popular approach applied to measure rental affordability is the housing cost approach, commonly named "rent-to-income ratio." This approach simply conceived housing affordability as the ratio between what households pay for their housing and what they earn. The approach presupposes that affordable rental-housing should cost only a certain percentage (usually about 2530 percent) of a household's monthly income (NDUBUEZE, 2009).

In a productive and high-cost city, households that spend 40 to 50 percent of their income on housing and still have resources for all their other needs; in a low-income city, 30 percent might be a stretch, even for a median income household. In the United States of America, affordability means a home, which costs less than 30 percent of a family's income, in either rent or a monthly mortgage. As rules of thumb, for rental housing, 30 percent of income is considered a threshold income reserved for rental payments. If the amount payable for housing is greater than 30 percent of household income, housing is considered unaffordable. Above this ratio, households are often referred to as suffering from "housing cost burdens." It has also become common to refer to those households spending more than half their income on housing as "severely" or "seriously" cost burdened((McKinsey Global Institute, 2014), (Cai, 2017).

\section{Results and Discussion}

\subsection{Affordability with respect to city size}

Level of rental affordability varies significantly with city sizes. Out of the entire sample respondents, 38.1 percent of the households were found to be unable to afford based on rent to income category assessment methods. 61.9 percent of housing units are affordable in the criteria of income allocation. The most affordable housing is found in Harer (75.6 percent) and Dire Dawa (65.9 percent) and the lowest is found in Jigjiga (41.8 percent). Compared with large and medium-sized cities level of affordability low in Jigjiga and the situation is found to be unique. These might be due to the difference in the level of informality of the housing sector and land supplies. In Jigjiga, urban land is under the ownership of leaders of the clan. So that land grabbing and an informal settlement are rare and hence, the supply of an informal rental unit is limited. Thus, as compared to Harar and Dire Dawa rent is less affordable. Whereas in Harar and Dire Dawa, many of rental service supplied within the informal sector and rent is relatively affordable.

To look into the level of differences in affordability, we can look at here. The variable city/town size is significant at 1 percent level of significance (p-value 0.000). For the variable city size, we have selected a large city as the base category. From the odd ratios or Exp (B) we can, therefore, say that a household renting a housing unit in a medium-sized city is 2.180 times more likely to afford for a rental unit than a household renting in a large city, keeping all other covariates constant. As we discussed in the previous paragraph, the experience of small-sized city is unique. A household renting a housing unit in a small sized city is only 0.441 times more likely to afford for a rental unit than a household renting in a large city, keeping all other covariates constant. The difference is the level of affordability for a small sized city is less than a large and medium-sized city.

\subsection{Rental housing stock}

The two major types of housing tenures that exist in Ethiopia are owner-occupied and rental occupations, though there are much cohabitation with an extended family and friends. In the domain of the rental option, the private sector, especially the informal one plays an active role in supplying rental houses. In addition, the government in 
its Kebele and government housing agencies have been supplying a rental housing service to great urban dwellers, particularly in large cities. Government rental houses are mainly the results of Proclamation No. 47/1975 which expropriates land and extra houses to the public. The government's, housing agency administration has a responsibility to administer monthly rental values of over 100 ETBs. Whereas, "Kebele houses" are urban houses which had been administered by the lowest city administration units (kebele administration) and its monthly rented value is below 100 ETB. Furthermore, rental housing agencies and city administrations have built additional units for low-income households and government officials, though its volume is insignificant. Census results of 2007 and WMS of 2016 indicated that the share of rental houses in is elevated from 45 percent to 53 percent and the reverse is true for the case of home ownership. Rental options covered around 54 percent of accommodation service in urban Ethiopia (CSA, 2016).

Disaggregated data within the rental sector indicated that in Dire Dawa the share of private rental units had been raised from 16,691 to 35643 (32.35 to 50.79 percent), in Harar elevated from 9,249 to 24130 (33.74 to 62.02 percent). For Jigjiga city level disaggregated, data on tenure type are unavailable. However, rental units are expected to grow significantly due to the rise in an urban population. Due to rapid urbanization, expansion of private and public investment and the rise in trade activates, the rental market is becoming a promising business for individuals who have extra units that can be rented out.

Table 2:-Housing Distribution among Different Tenure Types

\begin{tabular}{|c|c|c|c|c|c|c|c|c|c|c|c|c|}
\hline \multirow[t]{3}{*}{ Tenure Type } & \multicolumn{12}{|c|}{ Housing Units percentage } \\
\hline & \multicolumn{4}{|c|}{ Dire Dawa } & \multicolumn{4}{|c|}{ Harar } & \multicolumn{4}{|c|}{ Jigjiga } \\
\hline & \multicolumn{2}{|l|}{2007} & \multicolumn{2}{|c|}{2016} & \multicolumn{2}{|c|}{2007} & \multicolumn{2}{|c|}{2016} & \multicolumn{2}{|c|}{2007} & \multicolumn{2}{|c|}{2016} \\
\hline Owner occupied & 17,820 & 34.54 & 29881 & 42.58 & 8073 & 29.45 & 11225 & 28.85 & 18,706 & 54.02 & $24731 *$ & 54.02 \\
\hline All Rentals & 29078 & 56.35 & 35643 & 50.79 & 17005 & 62.03 & 24213 & 62.23 & 11560 & 33.38 & $15282 *$ & 33.38 \\
\hline $\begin{array}{ll}\begin{array}{l}\text { Rented } \\
\text { government }\end{array} & \text { from } \\
\end{array}$ & 11771 & 22.81 & & & 7562 & 27.58 & & & 2428 & 7.01 & & \\
\hline Private Rentals & 16,691 & 32.35 & & & 9,249 & 33.74 & & & 8967 & 25.89 & 11853 & 25.89 \\
\hline Other rentals & 616 & 1.19 & & & 194 & 0.71 & & & 165 & 0.48 & & \\
\hline $\begin{array}{lr}\text { Free } & \text { of } \\
\text { charges/subsidized/ }\end{array}$ & 4,697 & 9.10 & 4650 & 6.63 & 2,336 & 8.52 & 3470 & 8.92 & 4,363 & 12.60 & 5768 & 12.60 \\
\hline Total & 51595 & 100 & 70174 & 100 & 27414 & 100 & 38908 & 100 & 34,629 & 100 & $45781^{1 *}$ & 100 \\
\hline
\end{tabular}

Source: CSA (2007\& 2016)

\subsection{Determinants of rent affordability}

Empirical studies identified households ' composition, size, and income, structural or physical characteristics of housing units, non-housing expense, location, and neighborhood quality as a determinant factor that affects rental prices. Cost of housing, household's income, and availability of housing finance is critical factors in determining housing affordability.

3.3.1 Housing conditions

Housing conditions mainly attributed to livable rooms and the availability of basic amenities is amongst the determinants of rent affordability. The physical condition of existing housing units, which depend on the type of construction material used for walling, roofing and flooring, was essential for a comprehensive assessment of the quality of housing. To know exactly how much affordability with respected to room size and availability of basic services, lets a look at the results of logistic regression here. Results of the logistic regression analysis indicated that the variable room size is much at a 5 percent level of significance (p-value 0.020). Room size (1) (double room size) is significant at a 1 percent level of significance (p-value 0.001 ) and has an odds' ratio equals to 0.400 . For the variable room size, we have selected a single room as the base category. From the odd ratios or Exp (B) we can, therefore, say that a double sized room is 0.400 or 60 percent times less likely to be affordable than a single room unit, keeping all other covariates constant. Compared with the single sized room, a rental a unit having a three-room is 0.160 or 84 percent times less likely to be affordable, keeping all other covariates constant. The variable room size (3) (units that have four and above) is 0.098 or 90 percent $(1-0.098 * 100=90.2$ percent) times less likely to be affordable than a single sized room, keeping all other covariates constant. If a household shifting his rental units from a single sized room to multiple rooms, rental affordability will reduce significantly. Level of rental affordability varies significantly with the availability of basic amenities such as availability of private tape water, electricity and dining facilities. Rental unit having private tape water is much at a 1 percent level of significance ( $p$-value 0.071 ) and has an odd ratio equals to .637. This event implies rental units having tape water privately is 0.637 or 36.3 percent times less likely to be affordable than rental's units that have not private tape water, holding other variables constant.

\footnotetext{
${ }^{1}$ For Jigjiga Rental housing units are estimated by dividing the urban population by household size. By 2016 the total population of Jigjiga was 169390 and household size was 3.7 so that the housing unit is obtained by dividing the population by average household size i.e., 45781 housing units. On the other hand, disaggregated data on housing units is obtained by assuming the share of rental and owner-occupied housing units continued to constant.
} 


\subsubsection{Household composition and size}

The condition of a household, whether someone is single, married, divorced, or widow is an important variable in determining residential choice; whether to live independently from family or to live in cohabitation or to rent a house. The variable marriage status is significant at 1 percent level of significance ( $p$-value 0.003). For the variable marriage status, we have selected a single as the base category. Therefore, from the odd's ratios or Exp (B) we can say that a household marriage status (married, divorced or widowed) is .506 or nearly 50 percent times less likely to afford for a rental unit than a single household, keeping all other covariates constant. Compared with single households, residential choice of a couple is less flexible and forced to pay extra for a rental unit. The rate for a single unit of a rental unit to be rented for a single household against a couple differs as owners incurred extra cost for a marginal consumption of utilities.

3.3.3 Household Income and Expenditure on Rent

In examining how much housing affordability problems among varying income groups, it is imperative to evaluate the extent of income allocated to rent. Taking 30 percent of income as a threshold income reserved for rental payments, rental units incurred more than the threshold income is considered as not affordable and if it is below the threshold income rental unit is considered to be affordable. Accordingly, respondents were asked about their monthly income and how much they spent on rent. Based on the sample survey, 61.9 percent were affordable. About 38.1, percent of the housing units are not affordable to residents and 6.76 percent of sample respondents are highly burdened by rental expenditure (which they spent more than half of their income for rent payments)( Figure). Households that expend more than the threshold level is able to pay for rent by depriving them of their basic needs such as food and clothing. We found a household that spends more than what they earned during the field observation. The conditions were explained by living in cohabitation/sharing, and some have paid from family donations/remittance/ from extended families.

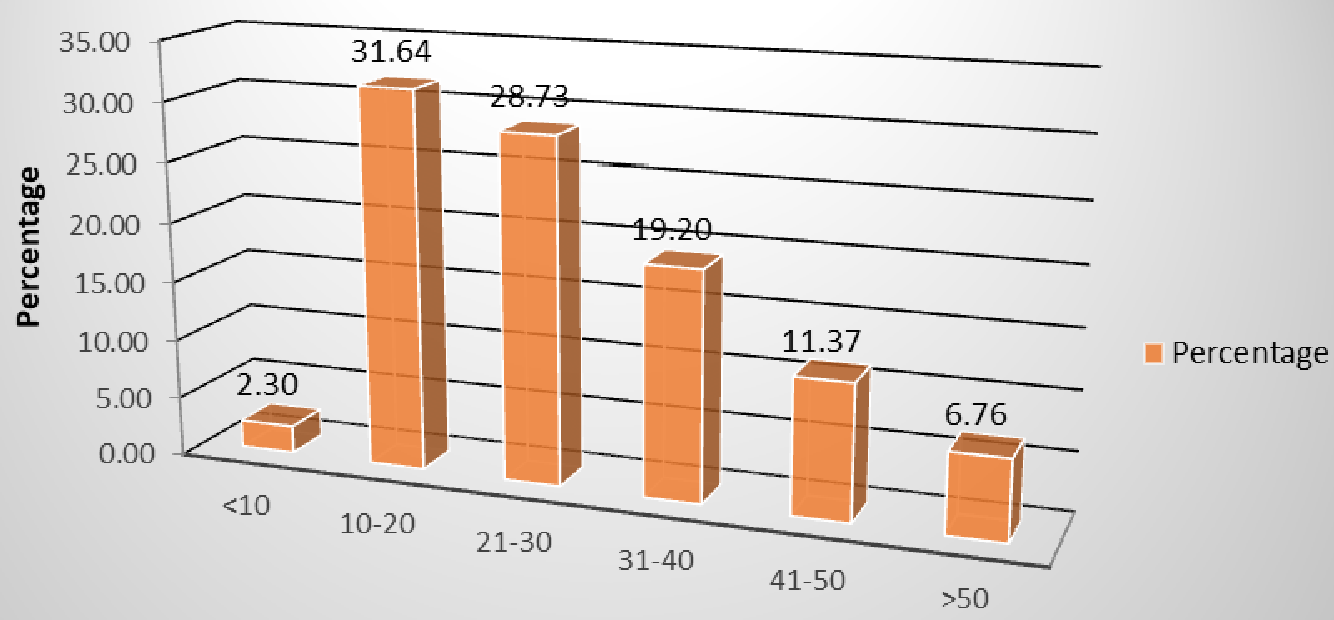

Percentage of Income expend on rent

Figure 1: Share of Income Allocated To Rent

Source: Compiled by Author, 2018

To understand how much rent affordability among different income groups, the results of logistic regression analyses have been discussed here. The variable household income is significant at the 1 percent level of significance (p-value 0.000). For the variable income, we have selected a monthly income less than 1600 ETB/month as the base category. From the odd ratios or Exp (B) we can, therefore, say that a household earns a monthly income 1600-3600 ETB/Month is 5.207 times more likely able to afford for a rental unit than a household earning less than $1600 \mathrm{ETB} /$ month, keeping all other covariates constant. The category income (2) (a household earns a monthly income of 3601-5600 ETB/Month) is 10.713 times more likely able to afford for a rental unit than a household earn less than $1600 \mathrm{ETB} /$ month, keeping all other covariates constant. The category income (3) (a household earns a monthly income of 5601-7600 ETB/Month) is 72.274 times more likely able to afford for a rental unit than a household earning less than $1600 \mathrm{ETB} / \mathrm{month}$, keeping all other covariates constant. The category income (4) (a household earns a monthly income of 7601-9600 ETB/Month) is 52.742 times more likely able to afford for a rental unit than a household earn less than $1600 \mathrm{ETB} / \mathrm{month}$, keeping all other covariates constant. The category income (5) (a household earns a monthly income over 9600 ETB/Month) is 41.615 times more likely able to afford for a rental unit than a household earn less than $1600 \mathrm{ETB} / \mathrm{month}$, keeping all other covariates constant. The result of the overall logistic regression shows the coefficient of income is statistically significant at 1 percent level of significance, income is positively related to rental affordability. 
Income is positively correlated with affordability because when the household income increases the ability to pay for housing is increased.

\section{Conclusion and Recommendation}

The paper and evaluated rental affordability and status of the rental housing units. After the evaluation of policy documents and review from literature, one can easily arrive at a conclusion that an attempt to make all citizens own their house is not a practical option let alone in developing countries, it was impossible to be realized in a developed nation where housing finance is easily accessible and regulatory institutions are strong enough to perform their duties properly. In realizing this in the recent period countries have developed their own rental housing policies. However, in the developing countries, the rental sector is a residual to alternatives of housing supply modalities and government at national or local levels are failed to allocate enough resources and failed to regulate it.

In Ethiopia, through the rental sector less emphasized in the government housing policies, the rental sector accommodates 54 percent of the housing needs. In Dire Dawa 50.79 percent, Harar 62.23 in Jigjiga 33.38 percent of the housing needs is served by rental options. These emphasized the need to get the issue on the larger urban policy agenda and gathered detailed information on the inner workings of rental housing, including the larger economic, political and social factors that affect rental supply and demand.

The result from African housing affordability report indicated that only 35.9 percent of households in urban Ethiopia can buy low-cost housing supplied at a construction cost of US\$ 7397. This event has an implication about whatever policy or regulatory interventions taken by government housing could not be accessible to lowincome households. Thus, policy orientation needs to be focused on improving households earning capacities and alter housing supply modalities from pro ownership to rental option.

The results of the logistic regression analysis indicated that household's income, the structure of the housing unit (single vs. multiform), household structure (single/divorced vs. married) and city/town size are significantly affecting rental affordability. The likely of rent affordability varies significantly with the change in household income. Income is positively correlated with affordability because when the household income increases the ability to pay for housing is increased. As well, the likelihood of rent affordability is decreases as numbers of rooms increased from a single size unit to many rooms and as we can shift from large sized city to medium sized city.

Over all about 61.9 percent of surveyed households were paid 30 percent or less of their monthly income to rent and 38.1 percent of a household were spent more than the thresholds' income level allocated to rent of rent to income category assessment methods. With this finding, one can conclude that the dominant households spent within the threshold level of income acceptable by international standards, however, the quality of the residential units is in a poor condition and households are forced to compromise a rental prices with the adequacy of the housing units.

Due to the inadequacy or low level of housing finances and inefficiency of residential land supply, residential choice of housing need of all income groups was limited to rental options and hence they are competing in the rental market. As a result, the residential choice of urban poor is highly constrained to stiff competition in price terms and hence forced to pay more than what they expected to pay in terms of income as well as forced to compromise housing quality with rent amount. Therefore, government intervention need to be focused on improving earning capacities for the low income household and stimulate developers as well as individual house builders through financial intermediary or mortgage financing.

\section{References}

Xi Li. (2011). Public Rental Housing Development in China-Comparative study with PRH Scheme in other countries. Department of Real Estate and Construction Management. Stockholm: Department of Real Estate and Construction Management.

Agency for Government Houses Establishment Proclamation No. 555/2007. (2007, Decembe 13). PROCLAMATION NO. 555/2007. A Proclamation To Establish The Agency For Government Houses. Addis Ababa.

Cai, Z. (2017). Analyzing Measurements of Housing Affordability. Washington D.C.: University of Washington. CSA. (2012). THE 2010/11 ETHIOPIAN HOUSEHOLDS CONSUMPTION - EXPENDITURE (HCE) SURVEY. Addis Ababa: CENTRAL STATISTICAL AGENCY (CSA).

CSA. (2016). WELFARE MONITORING SURVEY 2015/16. Addis Ababa: CENTRAL STATISTICAL Agency.

Green, R. K. (2011). Thoughts on Rental Housing and Rental Housing Assistance. Cityscape: A Journal of Policy Development and Research, 13(2), 39-55.

Gwayoung. Park, a. K. (2015). A study of Public Rental House supply by Using Urban Public Land. International Journal of Chemical, Environmental \& Biological Sciences (IJCEBS), 3(4), 290-294. 
Ismail, A. M. (2012). Multiple Regressions in Analysing House Price Variations. Communications of the IBIMA, http://www.ibimapublishing.com/journals/CIBIMA/cibima.html.

McKinsey Global Institute. (2014). A blueprint for addressing the global affordable housing challenge. New York.

Ministry of Urban Development, Housing and Construction (MUDHCo) . (2015). STATE OF ETHIOPIAN CITIES REPORT. Addis Ababa: Ministry of Urban Development, Housing and Construction (MUDHCo) .

NDUBUEZE, O. J. (2009). URBAN HOUSING AFFORDABILITY AND HOUSING POLICY DILEMMAS IN NIGERIA. Birmingham: Centre for Urban and Regional Studies School of Public Policy The University of Birmingham.

Norris, M., \& Winston, N. (2003). Housing Policy Review, 1990-2002. Dublin: Stationery Office.

Park, H.-A. (2013, April). An Introduction to Logistic Regression: From Basic Concepts to Interpretation with Particular Attention to Nursing Domain. J Korean Acad Nurs, 43(2).

Steve Pomeroy, J. H. (2015). Literature Review of International Rental Housing Policies. Montreal, Canada: Carleton University Centre for Urban Research and Education (CURE).

Taffin, I. G. (2013). Rental Housing Lessons from International Experience and Policies for Emerging Markets. Washington DC: World Bank.

UN-HABITAT. (2011). A policy guide to rental housing in developing countries: Quick Policy Guide Series (Volume 1). Nairobi: UNON, Publishing Services Section.

UN-HABITAT. (2003). Rental Housing: An essential option for the urban poor in developing countries. Nairobi: UN-HABITAT.

UN-HABITAT. (2008). Quick Guides for Policy Makers 1; URBANIZATION: The Role the poor play in urban development. Bangkok: UN-HABITAT.

Wickramaarachchi, N. (2016, February). Determinants of rental value for residential properties: A land owner's perspective for boarding homes. Built-environment: Sri Lanka, 12(1), 10-22.

World Bank. (2015). Stocktaking of the Housing Sector in Sub-Saharan Africa: Challenges and Opportunities. Washington DC: The World Bank. 
Vol.9, No.6, 2019

Annex 1: Results of logistic regression analysis

Variables in the Equation

\begin{tabular}{|c|c|c|c|c|c|c|c|c|}
\hline & & & & & & & 95\% C.I.1 & $\mathrm{EXP}(\mathrm{B})$ \\
\hline & B & S.E. & Wald & df & Sig. & $\operatorname{Exp}(\mathrm{B})$ & Lower & Upper \\
\hline City/Town Rank & & & 36.157 & 2 & $.000 *$ & & & \\
\hline City/Town Rank (1) & .780 & .249 & 9.772 & 1 & $.002 *$ & 2.180 & 1.337 & 3.555 \\
\hline City/Town Rank (2) & -.889 & .236 & 14.159 & 1 & $.000 *$ & 411 & .259 & .653 \\
\hline Marital Status (1) & -.680 & .229 & 8.818 & 1 & $.003 *$ & .506 & .323 & .794 \\
\hline Household Size & & & 1.282 & 3 & .733 & & & \\
\hline Household Size (1) & .036 & .221 & .026 & 1 & .871 & 1.037 & .672 & 1.600 \\
\hline Household Size (2) & -.220 & .368 & .355 & 1 & .551 & .803 & .390 & 1.652 \\
\hline Household Size (3) & .620 & .750 & .684 & 1 & .408 & 1.859 & .427 & 8.086 \\
\hline Income & & & 85.231 & 5 & $.000^{*}$ & & & \\
\hline Income (1) & 1.650 & .252 & 42.937 & 1 & $.000^{*}$ & 5.207 & 3.179 & 8.529 \\
\hline Income (2) & 2.371 & .317 & 55.796 & 1 & $.000 *$ & 10.713 & 5.750 & 19.960 \\
\hline Income (3) & 4.280 & .687 & 38.790 & 1 & $.000 *$ & 72.274 & 18.792 & 277.967 \\
\hline Income (4) & 3.965 & 1.143 & 12.032 & 1 & $.001 *$ & 52.742 & 5.611 & 495.740 \\
\hline Income (5) & 3.728 & 1.138 & 10.732 & 1 & $.001^{*}$ & 41.615 & 4.472 & 387.279 \\
\hline Room Size & & & 15.527 & 3 & $.001 *$ & & & \\
\hline Room Size (1) & -.917 & .285 & 10.388 & 1 & $.001^{*}$ & .400 & .229 & .698 \\
\hline Room Size (2) & -1.834 & .917 & 4.003 & 1 & $.045 * *$ & .160 & .027 & .963 \\
\hline Room Size (3) & -2.325 & 1.076 & 4.671 & 1 & $.031 * *$ & .098 & .012 & .805 \\
\hline Water (1) & -.451 & .250 & 3.260 & 1 & $.071 * * *$ & .637 & .390 & 1.039 \\
\hline Electricity (1) & -.145 & .557 & .068 & 1 & \begin{tabular}{|l}
.795 \\
\end{tabular} & .865 & .290 & 2.578 \\
\hline Kitchen Service (1) & -.101 & .225 & .199 & 1 & .655 & .904 & .582 & 1.406 \\
\hline Constant & -.914 & .419 & 4.754 & 1 & $.029 * *$ & .401 & & \\
\hline
\end{tabular}

Variable(S) Entered on Step 1: City/Town Size, Marital Status, Household Size, Income, Room Size, Water Access, Electric Access, and Kitchen Service.

Model summary

$* * *$ Significant at 10 percent; $* *$ Significant at 5 percent; $*$ Significant at 1 percent

$-2 \log$ likelihood $=684.650$

Cox \& Snell R Square $=0.242$

Nagelkerke R Square $=0.329$

Hosmer and Lemeshow Test

Chi-square $=10.085$ Df $=8$ Sig 0.259 